\title{
Incretin levels in patients with hypothyroidism and the evaluation of incretin levels alterations with treatment
}

\author{
Serkan Alemdar', Nusret Yilmaz', Sebahat Ozdem², Ramazan Sari ${ }^{1, *}$
}

Abstract

Background: Incretin hormones may influence the effects of thyroid hormones on insulin secretion, insulin resistance, and glucose metabolism. Thyroid hormones regulate insulin secretion, and the risk of diabetes was found to be associated with thyroid hormones.

Objectives: To determine whether incretin hormones influence the effects of thyroid hormones on insulin resistance and glucose metabolism.

Methods: A total of 26 patients were included in 2 groups consisting of 13 patients with hypothyroidism and 13 healthy controls. Levels of glucose, insulin, glucagon-like peptide 1 (GLP-1), and gastric inhibitory polypeptide (GIP) levels were measured in $0,30,60,90$, and 120th min during the oral glucose tolerance test in the control group and before and after thyroxine treatment in the hypothyroid group.

Results: In the hypothyroid group, waist circumference decreased after the euthyroid state was achieved $(P=0.026)$. No statistically significant differences were detected in the GLP-1 and GIP levels at baseline and 30, 60, 90, and 120 min between the hypothyroidism and control groups or after ensuring the euthyroid state in patients with hypothyroidism. Peak GLP-1 levels were observed at $30 \mathrm{~min}$ in the control group, whereas peak GLP-1 and GIP levels were detected at $90 \mathrm{~min}$ in the hypothyroidism group. After achieving the euthyroid state, peak GLP-1 and GIP levels were detected at $30 \mathrm{~min}$ as well.

Conclusion: In patients with hypothyroidism, the incretin hormones, especially the peak response of the incretin system, are significantly affected. Significant changes were observed in the incretin system by correcting hypothyroidism.

Keywords: glucagon-like peptide 1; hypothyroidism; incretins

Thyroid hormones induce a dose-dependent adverse effect on carbohydrate metabolism. For instance, in rats, while low doses of thyroid hormones and insulin increase glycogen synthesis, high doses of thyroid hormones accelerate degradation of liver glycogen to glucose. Thyroid hormones also affect the intestinal absorption rate, adipose tissue, and the intake rate of glucose by the muscles. On the other hand, thyroid hormones effectively and dose dependently increase the degradation of insulin [1-3]. In the case of thyroid hormone deficiency, the insulin response to glucose was found to be delayed in the oral glucose tolerance test (OGTT), and patients with hypothyroidism showed an increase in insulin sensitivity and a decrease in insulin degradation [4-7].

*Correspondence to: Ramazan Sari, Department of Internal Medicine, School of Medicine, Akdeniz University, Antalya 07058, Turkey, 
The incretin effect is defined as the difference in insulin secretion due to orally given glucose compared to that due to intravenous glucose, which would increase the plasma glucose level by the same amount [8]. This effect related to the intestine is associated with humoral or neural factors that are known as incretin and potentiate insulin secretion after enteral nutrition [9]. The incretin effect is responsible for 50\%-70\% of the insulin secretion occurring after oral food intake [10]. Glucagon-like peptide 1 (GLP-1) increases the beta cell mass, inhibits the apoptosis of beta cells, increases insulin synthesis and secretion, suppresses glucagon secretion, slows down the gastric drainage, and decreases the intake of food [9, 11-13].

Thyroid dysfunction and diabetes are the 2 most common endocrine disorders, and both these diseases are closely linked with each other [14]. It has been reported that thyroid hormones regulate insulin secretion, and the risk of diabetes was found to be associated with thyroid hormones $[15,16]$. Moreover, incretin hormones may influence the effects of thyroid hormones on insulin resistance, insulin secretion, and glucose metabolism.

In this study, our aim was to determine whether incretin hormones influence the effects of thyroid hormones on insulin secretion, insulin resistance, and glucose metabolism. To our knowledge, this is the first study to assess the exchange of incretin hormones before treatment and after ensuring the euthyroid state in patients with hypothyroidism.

\section{Materials and methods}

This study included patients with hypothyroidism $(\mathrm{N}=13)$ aged above 18 years who attended the Endocrinology Clinic of Akdeniz University Hospital and were kept under regular observation. These patients did not have any illness that would affect glucose and carbohydrate metabolism. Healthy individuals without any illnesses were also included as a control group $(\mathrm{N}=13)$. Patients aged $<18$ years and those diagnosed with diabetes mellitus, had undergone GIS surgery, had shown increased liver function test results for more than 2 times, and had creatinine levels $>1.5 \mathrm{mg} / \mathrm{dl}$ were excluded from the study. This study was approved by the Akdeniz University Medical Faculty Ethics Committee (approval no. B.30.2.AKD.0.20.05.06/69). Written informed consent was obtained from the patients.

\section{Laboratory evaluations}

All the assessments were performed after $12 \mathrm{~h}$ of fasting with the consent of the patients. Comprehensive medical history taking and physical examinations of the patients were performed. After anthropometric measurements, venous blood samples were used for assessing baseline laboratory parameters, including the levels of glucose, creatinine, alanine transaminase, total cholesterol, low-density lipoprotein (LDL) cholesterol, high-density lipoprotein (HDL) cholesterol, triglycerides, hemoglobin A1c, and insulin. Then, an OGTT was performed, in which $75 \mathrm{~g}$ of glucose was mixed in $300 \mathrm{ml}$ of water, and the patient was instructed to drink the prepared glucose solution within $5 \mathrm{~min}$. Venous blood samples were obtained for measuring the levels of glucose, insulin, GLP-1 (7-36), and total gastric inhibitory polypeptide (GIP) at 0,30 , 60,90 , and $120 \mathrm{~min}$. Blood samples for GLP-1 and GIP measurements were collected in BD brand (BDÔ P800) special tubes with a special content containing dipeptidyl peptidase$\mathrm{IV}$, esterase, and other protease inhibitors preventing the degradation of GLP-1 and GIP and centrifuged for $10 \mathrm{~min}$ at $+4^{\circ} \mathrm{C}$ and $3000 \mathrm{rpm}$. Then, the plasma samples were separated and stored at $-80^{\circ} \mathrm{C}$ until analysis.

The homeostasis model assessments of insulin resistance (HOMA-IR) scores of the patients were calculated by the formula insulin $(\mu \mathrm{U} / \mathrm{ml}) \times$ glucose $(\mathrm{mg} / \mathrm{dl}) / 405$ [17]

In addition, for patients with hypothyroidism, after ensuring the euthyroid state with thyroxine treatment, the tests were repeated, and the data from hypothyroid and euthyroid states were compared.

\section{Statistical analysis}

Statistical analyses were performed using SPSS version 20.0 software. Continuous variables were represented as median and minimum-maximum with mean \pm standard deviation. Categorical variables were expressed as frequency and percentage. One-sample Shapiro-Wilk test was performed to evaluate the normal distribution of the data. The MannWhitney test was used for the analysis of independent groups (hypothyroidism group and control group), and Wilcoxon signed ranks test was used for the comparison of the dependent groups (hypothyroid and euthyroid groups). While conducting the statistical analyses, the results were within the confidence interval of $95 \%$, and $P<0.05$ was considered as statistically significant.

\section{Results}

Age, body mass index (BMI), waist circumference, and HOMA-IR scores were similar between the hypothyroidism and control groups $(P>0.05)$. Serum thyroid-stimulating 
hormone (TSH) levels were higher in the hypothyroidism group than those in the control group $(16.5 \pm 10.1$ vs 1.99 $\pm 1.2 \mathrm{IU} / \mathrm{ml}, P=0.001)$. The serum TSH level was $2.2 \pm$ $1.9 \mathrm{IU} / \mathrm{ml}$ in the hypothyroidism group after treatment. There was no change in the BMI and HOMA-IR scores of the patients with hypothyroidism before treatment and after ensuring the euthyroid state $(P>0.05)$; however, there was a significant decrease in the waist circumference after ensuring the euthyroid state $(90.3 \pm 11.7$ vs $88.6 \pm 12.5 \mathrm{~cm}$, $P=0.026$ ).

The OGTT results revealed that 2 patients in the hypothyroidism group had impaired glucose tolerance, while 1 subject each in the control group had impaired fasting glucose and impaired glucose tolerance. Regarding the impaired glucose tolerance detected in the 2 patients with hypothyroidism, the condition improved in 1 patient in the euthyroid state, whereas it continued in the other patient. Moreover, in 1 of the patients in the control group, impaired fasting glucose was detected while in the euthyroid state unlike in the state of hypothyroidism.

Plasma glucose and insulin levels were similar in the hypothyroidism and control groups. There was also no change in the plasma glucose and insulin levels in patients with hypothyroidism before and after treatment (Table 1).

GLP-1 levels were increased after the glucose intake with OGTT in both the hypothyroidism and control groups. However, no statistically significant differences were detected in the GLP-1 levels at baseline and 30,60, 90, and $120 \mathrm{~min}$ between the hypothyroidism and control groups. Peak GLP-1 levels were observed at $30 \mathrm{~min}$ in the control group, whereas peak GLP-1 levels were detected at $90 \mathrm{~min}$ in the hypothyroidism group (Table 2).

GIP levels were increased after the glucose intake with OGTT in both the hypothyroidism and control groups, with no statistically significant difference observed between the groups. The highest GIP level was detected at $90 \mathrm{~min}$ in the control group, whereas in the hypothyroidism group, the highest GIP level was observed at $60 \mathrm{~min}$ (Table 2).

After ensuring the euthyroid state in patients with hypothyroidism, GLP-1 levels were found to be increased after the glucose intake with OGTT. However, there was no change in the GLP-1 levels measured in these patients after ensuring the euthyroid state when compared to those before treatment. In the hypothyroidism group, the highest GLP-1 level before treatment was detected at $90 \mathrm{~min}$, whereas the highest GLP-1 level after treatment was detected at $30 \mathrm{~min}$ (Table 2).

After ensuring the euthyroid state in patients with hypothyroidism, GIP levels were found to be increased after the glucose intake with OGTT. However, the GIP levels at baseline and 30,60, 90, and 120 min measured before treatment and after ensuring the euthyroid state in patients with hypothyroidism were found to be similar. In the hypothyroidism group, the highest GIP level was observed at 60 min before treatment, whereas the highest GIP level after treatment was detected at $30 \mathrm{~min}$ (Table 2).

Table 1. Plasma glucose and insulin levels in patients in the control group and in patients with hypothyroidism before treatment and hypothyroidism after treatment ${ }^{\dagger}$

\begin{tabular}{|c|c|c|c|c|c|}
\hline $\begin{array}{l}\text { Laboratory } \\
\text { parameters }\end{array}$ & $\begin{array}{l}\text { Control } \\
(n=13)\end{array}$ & $\begin{array}{l}\text { Hypothyroidism before } \\
\text { treatment } \\
\qquad(n=13)\end{array}$ & $\begin{array}{l}\text { Hypothyroidism after } \\
\text { treatment } \\
(n=13)\end{array}$ & $\begin{array}{c}P \text { (control vs hypothyroidism } \\
\text { before treatment) }\end{array}$ & $\begin{array}{c}P \text { (hypothyroidism } \\
\text { before vs after } \\
\text { treatment) }\end{array}$ \\
\hline \multicolumn{6}{|c|}{ Glucose levels (mg/dl) } \\
\hline Baseline & $87.46 \pm 6.85$ & $90.30 \pm 3.85$ & $90.38 \pm 7.24$ & 0.143 & 0.972 \\
\hline 30th min & $141.65 \pm 40.72$ & $145.92 \pm 22.38$ & $148.15 \pm 26.84$ & 0.343 & 0.753 \\
\hline 60th min & $139.47 \pm 45.79$ & $142.84 \pm 27.09$ & $128.30 \pm 28.31$ & 0.663 & 0.05 \\
\hline 90th min & $117.01 \pm 25.34$ & $121.69 \pm 34.48$ & $118.61 \pm 30.84$ & 0.939 & 0.610 \\
\hline 120th min & $96.60 \pm 30.78$ & $104.92 \pm 31.67$ & $102.89 \pm 29.95$ & 0.555 & 0.272 \\
\hline \multicolumn{6}{|c|}{ Insulin levels (mU/ml) } \\
\hline Baseline & $10.32 \pm 4.79$ & $8.24 \pm 3.31$ & $9.66 \pm 4.51$ & 0.191 & 0.152 \\
\hline 30th min & $\begin{array}{c}54.74(22.99- \\
294.3)\end{array}$ & $54.14(23.7-229.6)$ & $56.35(34.06-243.9)$ & 0.858 & 0.422 \\
\hline 60th min & $\begin{array}{c}56.32(18.53- \\
226.6)\end{array}$ & $69.95(23.87-160.7)$ & $53.43(28.7-146.7)$ & 0.59 & 0.116 \\
\hline 90th min & $46.7(7.9-121.8)$ & $42.75(8.1-127.1)$ & $42.94(9.36-208.5)$ & 0.957 & 0.753 \\
\hline 120th min & $\begin{array}{c}27.65(4.87- \\
132.7)\end{array}$ & $32.08(7.61-18)$ & $31.34(6.26-133.5)$ & 0.317 & 0.249 \\
\hline
\end{tabular}

${ }^{\dagger}$ Results are shown as mean \pm standard deviation for normal distribution and median (minimum-maximum) for abnormal distribution. 
Table 2. Plasma GLP-1 and GIP levels in patients in the control group and in patients with hypothyroidism before treatment and hypothyroidism after treatment

\begin{tabular}{|c|c|c|c|c|c|}
\hline $\begin{array}{l}\text { Laboratory } \\
\text { parameters }\end{array}$ & $\begin{array}{l}\text { Control } \\
(n=13)\end{array}$ & $\begin{array}{l}\text { Hypothyroidism } \\
\text { before treatment } \\
\qquad(n=13)\end{array}$ & $\begin{array}{l}\text { Hypothyroidism } \\
\text { after treatment } \\
\qquad(\mathrm{n}=13)\end{array}$ & $\begin{array}{c}P \text { (control vs } \\
\text { hypothyroidism before } \\
\text { treatment) }\end{array}$ & $\begin{array}{c}P \text { (hypothyroidism } \\
\text { before vs after } \\
\text { treatment) }\end{array}$ \\
\hline \multicolumn{6}{|c|}{ GLP-1 levels (pg/ml) } \\
\hline Baseline & $3.88 \pm 1.54$ & $3.90 \pm 1.47$ & $4.12 \pm 1.64$ & 0.93 & 0.67 \\
\hline 30th min & $5.63 \pm 1.74$ & $5.58 \pm 1.93$ & $6.01 \pm 2.40$ & 0.83 & 0.51 \\
\hline 60th min & $4.9 \pm 1.7$ & $5.0 \pm 2.1$ & $5.16 \pm 2.09$ & 0.74 & 0.59 \\
\hline 90th min & $4.47 \pm 1.73$ & $5.67 \pm 1.85$ & $5.53 \pm 2.21$ & 0.17 & 0.64 \\
\hline 120th min & $3.87 \pm 1.52$ & $4.50 \pm 1.01$ & $5.04 \pm 2.15$ & 0.29 & 0.15 \\
\hline \multicolumn{6}{|c|}{ GIP levels (pg/ml) } \\
\hline Baseline & $44.5 \pm 28.9$ & $55.1 \pm 18.7$ & $53.4 \pm 15.3$ & 0.59 & 0.74 \\
\hline 30th min & $81.1 \pm 31.9$ & $69.1 \pm 22.6$ & $87.1 \pm 21.9$ & 0.89 & 0.19 \\
\hline 60th min & $85.9 \pm 47.0$ & $79.1 \pm 32.7$ & $83.6 \pm 20.1$ & 0.94 & 0.14 \\
\hline 90th min & $96.5 \pm 42.7$ & $75.8 \pm 26.4$ & $74.2 \pm 16.5$ & 0.38 & 0.62 \\
\hline 120th min & $64.5 \pm 32.9$ & $68.4 \pm 33.1$ & $58.0 \pm 13.8$ & 0.56 & 0.54 \\
\hline
\end{tabular}

GIP, gastric inhibitory polypeptide; GLP-1, glucagon-like peptide 1 .

Area under the curve (AUC) for GLP-1 $(8.7 \pm 2.4$ vs $8.6 \pm$ $3.1, P=0.65)$ and GIP $(408.2 \pm 139.3$ vs $417.5 \pm 153.6, P=$ 0.45 ) in hypothyroidism and control groups, respectively, did not differ significantly. Reversal of hyperthyroidism to euthyroid status with antithyroid treatment did not induce significant changes in AUCs for incretins: $8.7 \pm 2.6$ vs $8.9 \pm 3.2, P=$ 0.85 , for GLP-1 and $408.2 \pm 139.3$ vs $415.3 \pm 151.9, P=0.67$, for GIP in hypothyroid and euthyroid states, respectively.

\section{Discussion}

Thyroid hormones have significant effects on glucose homeostasis. Therefore, a deficiency or an excess of thyroid hormones may induce changes in carbohydrate metabolism [18]. In hypothyroidism-induced rats, transformation of glycogen from glucose was found to be partially inhibited, along with a decrease in glucose transport and phosphorylation stimulated by insulin and disturbances in the phosphorylation of postreceptor insulin signaling proteins [19]. Clinical studies that have investigated insulin resistance in patients with hypothyroidism have reported contradictory results [20-26], which may be attributed to the methods used in the studies, the cause of hypothyroidism, the severity of hypothyroidism, and the different patient populations. Although some studies have reported that insulin resistance increased more specifically in the postprandial period than in the fasting period in hypothyroidism, a study that was carried out with a control group, 11 women with primary hypothyroidism, and 10 women with a euthyroid state showed that the HOMA-IR index did not differ between the 2 groups [21, 22]. Similarly, in our study, the HOMA-IR score was not different between the hypothyroidism and control groups [21-23]. Moreover, the HOMA-IR scores of patients in the hypothyroidism group remained unchanged after ensuring the euthyroid state with thyroxine treatment.

In the case of hypothyroidism, studies conducted on carbohydrate metabolism have reported that glucose absorption from the intestines is slower than normal. However, in our study, it was observed that fasting plasma glucose and fasting insulin and C-peptide levels were mostly similar to those in the control groups reported in some studies [22, 26, 27]. However, some studies have reported slightly high insulin and low glucose levels compared to the normal levels [23, 28]. In a study carried out by Nada, fasting glucose values remained unchanged; however, a significant increase in fasting insulin levels was detected in patients with hypothyroidism after ensuring the euthyroid state with treatment [26]. Another study carried out by Gimenez-Palop et al. showed that this increase in insulin levels did not reach a statistically significant difference after treatment [24]. In our study as well, fasting glucose and insulin levels remained unchanged in patients with hypothyroidism after the treatment.

In addition, as mentioned earlier, thyroid hormones are known to regulate insulin secretion, and the risk of diabetes was found to be associated with the level of thyroid hormones $[15,16]$. Assuming that thyroid hormones may affect glucose levels and insulin secretion, in the present study, after ensuring the euthyroid state before treatment and with treatment in patients with hypothyroidism, we evaluated the glucose levels and insulin secretion by performing OGTT.

In the case of patients with hypothyroidism, clinical studies related to the insulin response to glucose have shown 
contradictory results. The insulin response to an oral glucose load is variable; in some cases, it is observed to be higher than that in the control group, while it is sometimes delayed $[22,23]$. Handisurya et al. conducted a study aimed at detecting the changes in glucose metabolism before and after treatment in 11 patients with subclinical hypothyroidism and 12 patients with overt hypothyroidism, and they observed that the glucose-related insulin secretion was impaired, although it improved with treatment [29]. However, some studies have shown that, usually, the OGTT results do not show any abnormality; however, the peak value remained high in the second hour depending on the slowdown in gastric drainage and the delay in absorption $[22,28]$. In our study, we detected that the glucose and insulin responses of the patients in the hypothyroidism and control groups were similar when evaluated using OGTT. We also observed that the glucose response to OGTT performed after ensuring the euthyroid state with the treatment in the hypothyroidism group decreased at $60 \mathrm{~min}$. Supporting our study, Hays et al. also showed that the AUC for insulin secretion decreased by ensuring the euthyroid state [30].

As mentioned earlier, the incretin effect is responsible for $50 \%-70 \%$ of the insulin secretion occurring after oral food intake [10]. There are limited studies examining the relationship between thyroid hormones and the incretin system in the literature $[16,30]$. Considering the hypothesis that the incretin hormones may also influence the effects of thyroid hormones on insulin secretion, insulin resistance, and glucose metabolism, we evaluated the levels of GLP-1 and GIP by performing OGTT after ensuring the euthyroid state before treatment and with treatment in patients with hypothyroidism. To our knowledge, this is the first study that examined the incretin levels after ensuring the euthyroid state before treatment and with treatment in patients with hypothyroidism.

Studies evaluating the GIP response to baseline and glucose load in patients with hypothyroidism are also limited, and the results obtained are contradictory as well $[16,30]$. For instance, in the study conducted by Doong et al. exploring the effect of thyroid hormones on GIP secretion in rats, baseline plasma GIP levels were found to be higher in the hypothyroid rats than those in the euthyroid rats. Following oral glucose load in the euthyroid rats, an increase in the secretion of GIP was detected at $20 \mathrm{~min}$. The circulating GIP levels in the hypothyroid rats remained high from the 45th min to the 90th min compared to those in the euthyroid rats. In addition, the peak GIP response to glucose intake was not observed in thyroidectomized rats [16]. However, in another study in which Hays et al. evaluated the GIP response to oral glucose in patients with hypothyroidism, the GIP response to glucose was observed to be similar in the hypothyroid and euthyroid groups [30]. In our study, the GIP levels were found to be increased in both the hypothyroidism and control group after the glucose intake with OGTT. However, the GIP response induced by basal and glucose was observed to be similar in both groups. In the literature, the time in which the GIP level peaked with the glucose load varies between $30 \mathrm{~min}$ and $90 \mathrm{~min}$. While the highest GIP value was detected at $60 \mathrm{~min}$ in the hypothyroidism group in our study, the fact that the highest peak GIP value was detected at $90 \mathrm{~min}$ in the control group indicates that hypothyroidism may have an effect on the temporal variation of GIP response to a glucose load.

When the patients with hypothyroidism were evaluated in terms of GIP response after ensuring the euthyroid state with treatment in our study, it was observed that the GIP levels induced by baseline and glucose remained unchanged. Moreover, the fact that the highest peak GIP level was detected at 30 min after treatment, whereas the highest peak GIP level was observed at $60 \mathrm{~min}$ in the hypothyroidism group makes us to assume that the GIP response was temporally affected by ensuring the euthyroid state with the treatment.

The incretin effect is significantly dependent on GLP-1 levels. GLP-1 beta increases the cell mass, inhibits the apoptosis of beta cells, increases insulin synthesis and secretion, suppresses glucagon secretion, slows down the gastric drainage, and decreases the food intake [9,11-13]. Upon searching the literature, we did not find any important study examining the relationship between thyroid hormones and GLP-1 levels. In our study, the GLP-1 levels were found to be increased in both the hypothyroidism and control groups after the glucose intake with OGTT; however, no difference was observed in the GLP-1 levels at baseline and after OGTT between the hypothyroidism and control groups. While peak GLP-1 levels were detected at $90 \mathrm{~min}$ in the hypothyroidism group, the fact that the peak GLP-1 level was observed at $30 \mathrm{~min}$ in a manner that would comply with the results reported in the literature indicates that hypothyroidism caused a delay in the peak GLP-1 response.

In our study, GLP-1 levels measured after ensuring the euthyroid state with the treatment remained unchanged in patients in the hypothyroidism group. Nevertheless, in the hypothyroidism group, the highest GLP-1 level was detected at 90 min before the treatment and the highest GLP-1 level was detected at $30 \mathrm{~min}$ after the treatment. This finding makes us to assume that the delayed peak GLP-1 response to OGTT in the hypothyroidism group improved by ensuring the euthyroid state with the treatment.

The most important limiting factors of our study were that we could not evaluate the gastric drainage time and the limited number of patients included in the study. However, important 
data regarding the incretin system in patients with hypothyroidism were obtained despite these limitations. In patients with hypothyroidism, it was observed that, in particular, the peak responses of the incretin system hormones were considerably affected and considerable changes occurred in the incretin system with the improvement in hypothyroidism. Further studies with larger populations and calculating the gastric drainage time will contribute toward detecting the changes and the relationships among glucose, insulin, and incretin hormones in patients with hypothyroidism.

\section{Conclusion}

In patients with hypothyroidism, the incretin hormones, especially the peak response of the incretin system, are significantly affected. Significant changes were observed in the incretin system by correcting hypothyroidism.

Author contributions. SA and RS contributed substantially to the conception and design of this study. SA, NY, and SO contributed substantially to the acquisition of data. SA, SO, and RS analyzed and interpreted the data. SA and RS drafted the manuscript. NY and SO contributed substantially to its critical revision. All the authors approved the final version submitted for publication and take responsibility for the statements made in the published article.

Acknowledgment. This research did not receive any specific grant from funding agencies in the public, commercial, or notfor-profit sectors.

Conflict of interest statement. The authors have completed and submitted the ICMJE Uniform Disclosure Form for Potential Conflicts of Interest. None of the authors disclose any conflict of interest.

\section{References}

[1] Sinha RA, Singh BK, Yen PM. Thyroid hormone regulation of hepatic lipid and carbohydrate metabolism. Trends Endocrinol Metab. 2014; 25:538-45.

[2] Chidakel A, Mentuccia D, Celi FS. Peripheral metabolism of thyroid hormone and glucose homeostasis. Thyroid. 2005; 15:899-903.

[3] Boelaert K, Franklyn JA. Thyroid hormone in health and disease. J Endocrinol. 2005; 187:1-15.

[4] Mastracci TL, Evans-Molina C. Pancreatic and islet development and function: the role of thyroid hormone. J Endocrinol Diabetes Obes. 2014; 2:1044.

[5] Ujwal Upadya B, Suma MN, Srinath KM, Prashant A, Doddamani P, Shilpa SV. Effect of insulin resistance in assessing the clinical outcome of clinical and subclinical hypothyroid patients. J Clin Diagn Res. 2015; 9:OC01-4.

[6] Peppa M, Koliaki C, Nikolopoulos P, Raptis SA. Skeletal muscle insulin resistance in endocrine disease. J Biomed Biotechnol. 2010; 2010:527850.

[7] Duckworth WC. Insulin degradation: mechanisms, products, and significance. Endocr Rev. 1988; 9:319-45.

[8] Gautier JF, Choukem SP, Girard J. Physiology of incretins (GIP and GLP-1) and abnormalities in type 2 diabetes. Diabetes Metab. 2008; 34 Suppl 2:S65-72.

[9] Drucker DJ. The biology of incretin hormones. Cell Metab. 2006; 3:153-65.

[10] Nauck MA, Homberger E, Siegel EG, Allen RC, Eaton RP, Ebert R, Creutzfeldt W. Incretin effects of increasing glucose loads in man calculated from venous insulin and C-peptide responses. J Clin Endocrinol Metab. 1986; 63:492-8.

[11] Gautier JF, Fetita S, Sobngwi E, Salaün-Martin C. Biological actions of the incretins GIP and GLP-1 and therapeutic perspectives in patients with type 2 diabetes. Diabetes Metab. 2005; 31(3 Pt 1): 233-42.

[12] Perfetti R, Zhou J, Doyle ME, Egan JM. Glucagon-like peptide-1 induces cell proliferation and pancreatic-duodenum homeobox-1 expression and increases endocrine cell mass in the pancreas of old, glucose-intolerant rats. Endocrinology. 2000; 141:4600-5.

[13] Drucker DJ. Glucagon-like peptides: regulators of cell proliferation, differentiation, and apoptosis. Mol Endocrinol. 2003; 17:161-71.

[14] Perros P, McCrimmon RJ, Shaw G, Frier BM. Frequency of thyroid dysfunction in diabetic patients: value of annual screening. Diabet Med. 1995; 12:622-7.

[15] Crunkhorn S, Patti ME. Links between thyroid hormone action, oxidative metabolism, and diabetes risk? Thyroid. 2008; 18:227-37.

[16] Doong ML, Wang JW, Chung SC, Liu JY, Hwang C, Hwang CY, et al. Regulation of thyroid hormones in the secretion of insulin and gastric inhibitory polypeptide in male rats. Metabolism. 1997; 46:154-8.

[17] Muniyappa R, Lee S, Chen H, Quon MJ. Current approaches for assessing insulin sensitivity and resistance in vivo: advantages, limitations, and appropriate usage. Am J Physiol Endocrinol Metab. 2008; 294:E15-26.

[18] Brenta G. Why can insulin resistance be a natural consequence of thyroid dysfunction? J Thyroid Res. 2011; 2011:152850.

[19] Dimitriadis GD, Leighton B, Parry-Billings M, West D, Newsholme EA. Effects of hypothyroidism on the sensitivity of glycolysis and glycogen synthesis to insulin in the soleus muscle of the rat. Biochem J. 1989; 257:369-73.

[20] Rochon C, Tauveron I, Dejax C, Benoit P, Capitan P, Fabricio A, et al. Response of glucose disposal to hyperinsulinaemia in human hypothyroidism and hyperthyroidism. Clin Sci (Lond). 2003; 104:7-15

[21] Stanicka S, Vondra K, Pelikánová T, Vlcek P, Hill M, Zamrazil V. Insulin sensitivity and counter-regulatory hormones in hypothyroidism and during thyroid hormone replacement therapy. Clin Chem Lab Med. 2005; 43:715-20.

[22] Dimitriadis G, Mitrou P, Lambadiari V, Boutati E, Maratou E, Panagiotakos DB, et al. Insulin action in adipose tissue and muscle in hypothyroidism. J Clin Endocrinol Metab. 2006; 91:4930-7.

[23] Maratou E, Hadjidakis DJ, Kollias A, Tsegka K, Peppa M, Alevizaki $\mathrm{M}$, et al. Studies of insulin resistance in patients with clinical and subclinical hypothyroidism. Eur J Endocrinol. 2009; 160:785-90. 
[24] Gimenez-Palop O, Giménez-Pérez G, Mauricio D, Berlanga E, Potau N, Vilardell C, et al. Circulating ghrelin in thyroid dysfunction is related to insulin resistance and not to hunger, food intake or anthropometric changes. Eur J Endocrinol. 2005; 153:73-9.

[25] Singh BM, Goswami B, Mallika V. Association between insulin resistance and hypothyroidism in females attending a tertiary care hospital. Indian J Clin Biochem. 2010; 25:141-5.

[26] Nada AM. Effect of treatment of overt hypothyroidism on insulin resistance. World J Diabetes. 2013; 4:157-61.

[27] Krassas GE, Pontikides N, Loustis K, Koliakos G, Constantinidis T, Kaltsas T. Resistin levels are normal in hypothyroidism and remain unchanged after attainment of euthyroidism: relationship with insulin levels and anthropometric parameters. J Endocrinol Invest. 2006; 29:606-12.

[28] Shah JH, Motto GS, Papagiannes E, Williams GA. Insulin metabolism in hypothyroidism. Diabetes. 1975; 24:922-5.

[29] Handisurya A, Pacini G, Tura A, Gessl A, Kautzky-Willer A. Effects of T4 replacement therapy on glucose metabolism in subjects with subclinical $(\mathrm{SH})$ and overt hypothyroidism $(\mathrm{OH})$. Clin Endocrinol (Oxf). 2008; 69:963-9.

[30] Hays JH, Silverman E, Potter BB, Shakir KM. Normal gastric inhibitory polypeptide response to oral glucose in hypothyroidism. J Endocrinol. 1994; 140:309-12. 